\title{
MORAR EM 2025: UM ESTUDO SOBRE A VERTICALIZAÇÃO DAS CIDADES, O POTENCIAL DO LIXO ORGÂNICO E O REUSO DE RECURSOS NATURAIS EM AMBIENTES RESIDENCIAIS COMPARTILHADOS
}

\author{
Elisangela Manarim Guimarães \\ Universidade da Região de Joinville - UNIVILLE \\ elismanarim@gmail.com \\ Morgana Creuz Ganske \\ Universidade da Região de Joinville - UNIVILLE \\ morganacreuz.mc@gmail.com
}

Resumo: Este artigo objetiva a geração de alternativas conceituais para o aproveitamento do potencial do lixo orgânico e reuso de recursos naturais (consumo de água) para melhoria da qualidade de vida em ambientes residenciais verticalizados, vislumbrando o ano de 2025. Para tal foram analisadas as tendências Urban Jungles, Home \& Share e Utopias Cotidianas, visando o entendimento do cenário, as projeções para o futuro e o comportamento do consumidor. A metodologia projetual utilizada evidencia o duplo diamante, composta de quatro fases segmentadas: descobrir, definir, desenvolver e entregar. Os resultados obtidos, fortalecem os estudos sobre o potencial do lixo, a verticalização das cidades aliada à sustentabilidade, o reuso de recursos naturais e a utilização de áreas compartilhadas. Dessa forma, a alternativa conceitual desenvolvida: uma horta comunitária localizada no terraço dos prédios, utiliza o potencial do lixo orgânico como adubo, após processo de compostagem, e o reuso da água dos apartamentos e da chuva para a sua irrigação. A proposta visualiza um ambiente mais sustentável, em que as pessoas vivenciem um estilo de vida mais saudável e consciente, vivendo nos espaços urbanos, sem abdicar de experiências junto a atmosfera verde.

Palavras-chave: verticalização das cidades; lixo orgânico; recursos naturais; áreas compartilhadas; design sustentável.

Abstract: This article aims to generate conceptual alternatives for the potential use of organic waste and reuse of natural resources (water consumption) to improve the quality of life in residential environments upright, seeing the year 2025. To this end was analyzed the trends of Shared Areas, Urban Jungle and Utopias Living, aimed at understanding the scenario, the projections for the future and consumer behavior. The methodology applied shows a double diamond, made up of four phases segmented into two diamonds. The first diamond, aim to discover and define the focus of approach, the second, approach the phases develop and deliver. The results obtained strengthen the studies on the waste potential, 
verticalization of the cities combined with sustainability, reuse of natural resources and the use of shared areas. In that way, the conceptual alternative developed: a community garden located on the terrace of buildings uses the potential of organic waste as fertilizer after composting process, and the reuse of water from the apartments and rain for their irrigation. The proposal displays a more sustainable environment for people to experience a healthier and conscious lifestyle, living in urban areas, without giving experiences along the green surroundings.

Keywords: verticalization of cities; organic waste; natural resources; shared areas; sustainable design.

\section{INTRODUÇÃO}

A temática morar em 2025 norteou o desenvolvimento projetual deste artigo, que é resultado da disciplina Desenvolvimento de Produtos I, do Programa de Mestrado Profissional em Design, da Univille. Baseando-se no cenário atual das cidades, utilizou-se como característica primária a verticalização residencial dos espaços urbanos. Em paralelo, foram abordados o potencial do lixo orgânico e o reuso de recursos naturais, visto que estudos divulgados pelo Banco Mundial apontam que até 2025 , a produção de lixo aumentará $70 \%$ em todo o mundo (DN, 2012, web). A quarta característica estudada é a utilização de espaços compartilhados, visto a pouca metragem quadrada dos apartamentos. Serviços antes individuais vêm conquistando aspecto compartilhado, cita-se como exemplo as lavanderias nos condomínios, áreas de festa e convivência. Conforme Publicitta (2015, web), estas modalidades de serviço, "aliam mobilidade, eficiência, economia e otimização de espaço, dinheiro e tempo".

Utilizou-se como metodologia projetual o diagrama do duplo diamante, proposto pelo United Kingdom Design Council, em 2005. A metodologia é organizada em quatro etapas, sendo separadas em duas fases em cada diamante. No primeiro estão as fases descobrir e definir, já no segundo estão as etapas desenvolver e entregar. No primeiro diamante, analisou-se o cenário da verticalização das cidades, as questões do lixo na sociedade e o consumo da água. Em paralelo foram observadas as tendências para os próximos anos, no que tange o desenvolvimento de produtos e serviços: Urban Jungles e Home \& Share. Juntamente, analisou-se as tendências de comportamento dos consumidores e estilo de vida mediante o cenário apresentado: Utopias Cotidianas. No segundo diamante, realizou-se o desenvolvimento projetual apresentando as alternativas geradas com base no processo apresentado.

Tendo como base os dados do UNFPA - Fundo de Populações das Nações Unidas (2007), verifica-se que a estimativa de pessoas residindo em áreas urbanas é de $61 \%$. Se comparado com os $34 \%$ na década de 60 , percebe-se que este número quase que dobrará. Diante desse contexto, observa-se a crescente verticalização das cidades. No Brasil, este conceito apresenta-se em sua maioria na habilidade habitacional, segundo Souza (1994) esta pode ser considerada uma identidade brasileira, visto que em outros lugares mundiais o foco é industrial e comercial.

$\mathrm{O}$ aumento populacional nas cidades acarreta em consequências para os espaços urbanos, das quais destaca-se o aumento da produção do lixo e o consumo imoderado de água. Segundo a EBRELPE - Associação Brasileira de Empresas de 
Limpezas Pública e Resíduos, em 2013 mais de 76 milhões de toneladas de lixos sólidos foram gerados nas cidades, sendo que destes, apenas 58,3\% teve uma destinação adequada. Em 2010, o governo sancionou a Lei 12.305, que regulamenta o descarte correto do lixo sólido, visando o fim dos lixões. A meta era ter $20 \%$ do lixo reciclado até 2020, mas de acordo com o diretor do Ministério do Meio Ambiente Sérgio Gonçalves (2011), isso está longe de acontecer. Outra consequência do aumento populacional é o consumo descomedido de água. Aliado a fatores como o aumento populacional e as alterações climáticas, que têm deixado algumas regiões sem chuvas suficientes para encher os reservatórios, gerou-se uma crise hídrica alarmante (COEHN, 2015, web). De acordo com o Relatório Mundial das Nações Unidas sobre o Desenvolvimento de Recursos Hídricos (2015), caso os padrões atuais de consumo de água sejam mantidos, até o ano de 2030 haverá no mundo um déficit de 40\% no abastecimento de água.

Partindo da problemática: como utilizar a verticalização residencial, por meio do aproveitamento do potencial do lixo orgânico e recursos naturais para a criação de um ambiente compartilhado, desenvolveram-se alternativas para adaptação estrutural visando a sustentabilidade. A proposta: uma horta compartilhada, utilizando o potencial do lixo orgânico, por intermédio da compostagem, como adubo para a horta e o reuso da água de alguns ambientes dos apartamentos, bem como a coleta da água da chuva, para irrigação desta, de jardins, limpeza das áreas comuns dos prédios e descarga de apartamentos. Por meio de alternativas como estas, busca-se morar em 2025 em ambientes mais sustentáveis e que proporcionem uma melhor qualidade vida aos indivíduos e ambiente como um todo.

A estrutura desse artigo é formulada em três etapas, de modo que na primeira fase explana-se o estado da arte do cenário de verticalização das cidades, a questão do lixo na sociedade e o consumo de água. A segunda fase reflete sobre as tendências para os próximos anos e sobre o público alvo deste projeto. Já na terceira fase, enfocase no desenvolvimento projetual e apresentação das alternativas.

\section{DESENVOLVIMENTO}

O presente artigo tem como intenção a projeção de possibilidades para o conceito de morar em 2025. Dessa forma, este projeto tem como objetivo a geração de alternativas para aproveitamento do potencial do lixo orgânico e reuso de recursos naturais (água) para melhoria da qualidade de vida em ambientes residenciais verticalizados. Na sequência, serão abordadas as temáticas fundamentais para desenvolvimento projetual.

\subsection{O ESPAÇO URBANO E A VERTICALIZAÇÃO DAS CIDADES}

As cidades se configuram como lugares concretos e materiais, em que destacam-se as ruas, casas, edifícios residenciais e comerciais, pontes, praças, entre outros e lugares abstratos, que contam as histórias das pessoas que vivem nela, as lembranças, marcos do cotidiano. Ou seja, as cidades são lugares de interação e de convivência que se configuram como plano de fundo da vida de seus cidadãos (LYNCH, 2011; SANTOS, 1992).

Sabe-se que a população mundial aumenta consideravelmente ano após ano. Segundo o Worldometers (2015, web) site que quantifica em tempo real diversos dados sobre a população mundial, o número de habitantes do planeta, ultrapassa a 
contagem de 7 bilhões de pessoas, entretanto dados apontam que o aumento dos indivíduos ocorre de forma desacelerada nos últimos anos, sendo ainda representativa nos países subdesenvolvidos (IBGE, 2015, web). Conforme a Organização das Nações Unidas, na década de 60, a porcentagem de pessoas que viviam em áreas urbanas era de $34 \%$, quatro décadas depois, nos anos $2000,53 \%$ das pessoas residiam nas cidades, sendo que a previsão para o ano de 2025 é que em média $61 \%$ de toda a população mundial viva nos espaços urbanos (UNFPA, 2007). As explicações para esta migração são diversas, entretanto destacam-se a mecanização agrícola e principalmente a busca por melhores condições de vida. A alta concentração de pessoas nas cidades resultou em inúmeros problemas de urbanização, infraestrutura e planejamento urbano ao redor do mundo, apresentando características diferenciadas em cada região. Na América Latina, a falta de oportunidades de trabalho gerou um incremento na população considerada pobre, ocasionando o aumento de favelas e o crescimento da economia informal (SANTOS, 2011).

A complexa imagem dos espaços urbanos vem se reconfigurando desde a década de 70, quando o processo de verticalização das cidades foi iniciado. Santos (2011) salienta que o espaço urbano contemporâneo se destaca como produto do capitalismo, em que se ressalta a mais-valia. Souza (1994, p.129) afirma que a verticalização residencial das cidades faz parte da identidade brasileira, visto que "em nenhum lugar do mundo o fenômeno se apresenta como no Brasil, com o mesmo ritmo e com a mesma destinação prioritária para a habitação". A autora destaca que em outros países, a verticalização das cidades destina-se a fins comerciais em primeiro plano. Conforme Mendes (1992) e Giménez (2007) a verticalização do espaço urbano é um processo de reprodução do solo, visto que o mesmo espaço de terra serve de moradia para diversas famílias. $O$ fato da verticalização destinar-se em grande parte a habitação em território nacional segundo Santos (2011), é devido as iniciativas governamentais de apoio ao financiamento habitacional.

Os condomínios residenciais surgiram há mais de quatro décadas como alternativa para ampliação da oferta imobiliária e secundariamente como uma opção mais segura e tranquila para residir. Sabe-se que o ambiente em que as pessoas moram são considerados refúgios, visto que este é um ambiente para descanso, descontração e vivência familiar. É neste espaço que inúmeras atividades cotidianas são realizadas e o fato de abrigar inúmeras pessoas e família, faz com que os condomínios criem comunidades (SILVEIRA \& SILVEIRA, 2014). Conforme Pedro (2002, p. 20) "[...] a habitação influencia sobre múltiplos aspectos o dia a dia dos moradores, marcando a sua qualidade de vida e as suas expectativas e possibilidades de desenvolvimento futuro". Silveira e Silveira (2014) afirma que ao medir a qualidade de vida, vários critérios objetivos e subjetivos estão sendo analisados, dos quais destacase a condição ambiental do espaço. Nesse contexto, Herculano (2000) e Byun (2011) destacam que a qualidade do ar, saúde do ambiente, equipamentos coletivos urbanos, bem como a presença de ambientes naturais em meio ao espaço urbano que assegurem o pluralismo ambiental, reforçam este contexto de qualidade de vida.

Percebe-se que a cada dia a sustentabilidade conquista mais destaque. Independente da área: industrial, comercial, social ou residencial, diversas são as alternativas implantadas para contribuir com esta tendência. Ressalta-se que a sustentabilidade é segmentada em três esferas: ambiental, social e econômica. Diante desse contexto, percebe-se que os condomínios residenciais vêm aderindo ao 
movimento e implantando soluções para melhorar a qualidade de vida dos indivíduos que nele residem e em consequência do próprio ambiente como um todo (BRIAN, 2008). Tal conceito reflete uma contra tendência à imposta pela Revolução Industrial. Medeiros e Nardi (2012, web) afirmam que este acontecimento marcou para sempre a história do planeta, visto que em sua decorrência o capitalismo se expandiu e o meio ambiente ficou em segundo plano, sendo constantemente negligenciado.

O processo de verticalização das cidades é percebido de forma polêmica, visto que alguns estudiosos refletem sobre os benefícios de uma cidade compacta, enquanto outros alertam para os prejuízos a estrutura urbana. Rueda (1996), Myers (1990) e Yeang (2002) reforçam o conceito de cidades compactas, sustentáveis, diversas, concentradas e densificadas, ao destacar que a concentração de atividades nos locais, reforça as relações locais, encurtam caminhos e incentivam a caminhabilidade. Silveira e Silveira (2014, web) sinalizam que o conceito de cidades compactas deriva da Europa e que este sistema "visa, sobretudo, reduzir os custos da construção material, de infraestruturas, propiciando circulação mais eficiente e menos dispendiosa, e reduzindo a necessidade de expansão sobre novas áreas naturais". Autores como Nucci (2008) e Caro e Rivas (1990) divergem desta abordagem ao defender que tal sistema pode ocasionar alterações no espaço físico, acarretando em alterações climáticas, problemas de drenagem, cobertura vegetal, conforto térmico, na mobilidade, na tranquilidade pública e na qualidade do ar. $O$ fato é que a verticalização atingiu níveis altos de aderência e são consideradas uma das grandes tendências futuras para habitação. Compreender o contexto do lixo na sociedade e de que forma a água é consumida se faz necessário visto que os problemas que o aumento deste e a escassez daquela proporcionam. Dessa forma, no próximo tópico é realizado um levantamento teórico a cerca destas temáticas.

\subsection{LIXO E RECURSOS NATURAIS}

Analisando a situação ambiental do país, observa-se pontos relevantes que influenciam diretamente toda a sociedade, como por exemplo o descarte de lixo e o consumo de água, estes encontram-se em condições precárias devido a diversos problemas. O lixo, mesmo com uma lei que regulamenta sua forma e locais de descarte, ainda é jogado em lixões a céu aberto em sua grande maioria. A água que está sendo racionada em algumas regiões, oportuniza a maior crise hídrica no país. Dessa forma na sequência, apresenta-se um panorama geral sobre tais questões.

\subsubsection{O lixo na sociedade}

Cada pessoa no Brasil produz uma média de $1,0 \mathrm{~kg}$ à $1,5 \mathrm{~kg}$ de lixo por dia, somando durante um mês, esse número pode chegar à $45 \mathrm{~kg}$, pensando em um ano chegaria à $540 \mathrm{~kg}$ por pessoa, e o grande problema é que a maior parte deste lixo ainda não tem o tratamento adequado, indo para lixões a céu aberto. Segundo a EBRELPE (Associação Brasileira de Empresas de Limpezas Pública e Resíduos) em 2013 mais de 76 milhões de toneladas de lixos sólidos foram gerados nas cidades, cerca de $4,1 \%$ a mais que em 2012, sendo que apenas $58,3 \%$ dos resíduos sólidos tem um destino adequado. Se continuar neste crescente, em 2025 estarão sendo produzidos $41 \%$ a mais de lixo do que já se produz hoje.

O Brasil é o terceiro país que mais produz lixo no mundo, ficando atrás somente dos Estados Unidos e do Japão. Todo lixo produzido traz problemas, mas estes podem 
ser solucionados com pequenas atitudes, como o simples fato de separar o lixo em casa. Hoje já existem muitas cooperativas que fazem a coleta e separação do lixo reciclável, mas como observa a especialista em planejamento de limpeza urbana do Distrito Federal Juliana Berber, nem tudo que tem potencial de reciclagem consegue ser devidamente separado e ter o destino adequado.

Atualmente já existem em alguns prédios empresas especializadas na coleta de lixo, como é caso do Instituto Muda de São Paulo fundado por Alexandre Furlan que desenvolve trabalhos de reciclagem. Acredita-se na efetividade do sistema com treinamento e colaboração dos moradores, "para que um projeto de coleta seja um sucesso, o primeiro passo é fazer um bom planejamento como qualquer outro projeto", relata Furlan (2014, web). Serão iniciativas e soluções como estas que ajudarão a melhorar a situação do Brasil com relação ao descarte do lixo.

O crescimento do lixo está ligado diretamente ao excesso de consumo gerado pelo capitalismo, este aumento da produção de lixo está trazendo um sério problema socioambiental. Para ter um futuro melhor é necessário reciclar, reduzir, reutilizar, refazer planejamentos e reeducar as pessoas visando a redução da geração de lixo, separação eficiente dos itens, visando atitudes mais sustentáveis.

\subsubsection{Consumo da Água}

O Brasil sempre teve um grande potencial de água, possuindo cerca de $12 \%$ da água doce disponível na Terra (ANDREU, 2012). Entretanto este cenário vem mudando e reflexos podem ser percebidos com as crises hídricas registradas principalmente no sudeste e nordeste. A água é um bem comum, que o ser humano, os animais, os vegetais, ou seja, todo o meio ambiente necessita para sua sobrevivência. Segundo Victorino (2007) "considerando ser a água nosso precioso recurso natural, responsável pela vida e sustentação do planeta é extremamente oportuna divulgar a importância deste bem". Não existiria vida no planeta se não houvesse água, a cada dia está mais escassa por vários motivos, como a poluição dos rios, a falta de chuvas, o consumo exacerbado entre outros. O problema da crise das águas está ligado a questões governamentais, de gerenciamento, mais até do que de recursos, a própria UNESCO afirma que devem acontecer mudanças na administração pública com relação a forma de gerir a distribuição das águas, recomenda ainda investimentos em infraestrutura e educação, para garantir um futuro com água para todos. Segundo professor Ary Mergulhão (UNESCO) "o Brasil deve investir em diagnóstico para saber como está a política de consumo, atenção à população e planejamento. É um trabalho continuo todos tem que se preocupar com a situação".

Ainda se está longe de chegar há um padrão sustentável para a água, mas não se pode parar, pois o consumo de água é vital para a vida, com tudo se os padrões atuais forem mantidos até 2030 haverá no mundo déficit de $40 \%$ no abastecimento de água, de acordo com o relatório mundial das nações unidas sobre desenvolvimento de recursos hídricos 2015 - água para um mundo sustentável, uma situação bem preocupante para todos os seres vivos do planeta.

É com base neste panorama que muitos condomínios e prédios estão adotando medidas de conscientização com seus moradores, separando a fatura da água para que cada um possa ver e sentir o quanto realmente gasta, isso faz com que as pessoas comecem a economizar água para economizar dinheiro, outros adotam estratégias mais sustentáveis, como a reutilização da água limpa. As águas utilizadas nas máquinas 
de lavar louça e do banho por exemplo podem ser utilizadas para limpeza do prédio, a vassoura pode ser a melhor aliada nesta batalha de economizar água, utilizando-a para a limpeza de áreas externas como calçadas no lugar de usar a mangueira da água, ato que gera grande desperdício deste bem natural. Por fim ter consciência ao utilizar a água em sua residência, é a melhor forma de economizar, a conscientização, a reeducação no uso deste precioso bem, fará a diferença para um futuro sustentável.

\subsection{TENDÊNCIAS PARA O DESENVOLVIMENTO DE PRODUTOS E SERVIÇOS}

Observa-se que o espaço urbano está a cada dia diminuindo, visto a intensa utilização dos lugares e o aumento da demanda por espaços parar morar, trabalhar, se divertir ou ainda para melhorar a infraestrutura urbana. $O$ fato é que as cidades estão se verticalizando e o resultado disso é o compartilhamento de áreas comuns e a necessidade de manter contato com a natureza. O compartilhamento de lugares também está retornando, valorizando os laços entre as pessoas e a diminuição da individualização. Dessa forma, apresentam-se três tendências para produtos e serviços que serão utilizadas como base neste projeto: Home \& Share (PUBLICITTA, 2015, web; PUBLICITTA, 2015, web; FAST COMPANY, 2015, web); Urban Jungle (URBAN JUNGLE BLOGGERS, 2015, web) e a macrotendência Utopias Cotidianas (WGSN, 2014, web).

\subsubsection{Home \& Share}

Com o crescimento da população nos centros urbanos, a falta de espaço é real. Dessa forma, designers, arquitetos e engenheiros preocupados com tal situação estão propondo soluções para este problema, utilizando com mais frequência espaços compartilhados. Uma forte tendência citada pela revista Publicitta (2015, web), é a de áreas compartilhadas, proporcionando mais espaço, e por consequência mais oferta de moradia. Tal tendência é baseada no conceito difundido nos Estados Unidos e Europa nomeado Home \& Share (FERRO, 2015, web; PUBLICITTA, 2015, web). Nesta tendência observa-se que a troca de experiências, objetos e a convivência com outras pessoas são estimuladas. Atualmente percebe-se mais espaços compartilhados em prédios e condomínios, como por exemplo as áreas de festa, playground, brinquedoteca, lavanderias, estes são mais comuns, mas o investimento nesta área está crescendo. Com o fortalecimento desta tendência, prevê-se para poucos anos novas modalidades de compartilhamento, dos mais comuns aos mais inusitados.

\subsubsection{Urban Jungles}

A cidade, como plano de fundo do cotidiano dos seus moradores, está experimentando um novo olhar sobre como viver de forma mais sustentável nos centros urbanos. A tendência Urban Jungle, ressalta a selva urbana, onde encontramse indivíduos que valorizam a natureza, as plantações caseiras, o cultivo de hortas comunitárias e o cuidado com o meio ambiente (URBAN JUNGLE BLOGGERS, 2015, web). A tendência Urban Jungle é observada nas indústrias da moda e das cores, com influências nas áreas de decoração, desenvolvimento de produtos e no campo das construções sustentáveis. A Pantone utilizou a tendência como inspiração de sua cartela de cores para o ano de 2015, afirmando que esta transforma o caos das metrópoles em ambientes mais civilizados e campestres (PANTONE, 2015, web). Conforme a Atkins Global (2012, web), escritório de design e engenharia responsável pela consultoria na construção do parque olímpico de Londres, em 2012, atentar para 
tal tendência é fundamental para preservação do ambiente natural. Evidenciam ainda que construções verdes, contribuem para minimizar gastos com recursos energéticos, de água, melhoram a oxigenação, além de auxiliarem na preservação do meio.

\subsubsection{Utopias Cotidianas}

Vive-se em uma cidade agitada, em que o tempo está mais escasso e as pessoas com o nível de stress elevado. Dessa forma a macrotendência Utopias Cotidianas, apontada pelo instituto de pesquisa WGSN (2014, web), revela um comportamento dos indivíduos que estão resgatando as coisas simples da vida. Tal macrotendência é segmentada em três micro tendências: Viceless (vida sem excessos e sem vícios), Micro Adventures (espaços para pequenas fugas do dia a dia) e Revolution (considera o amor como combustível da contemporaneidade). Modolin, gerente de contas da WGSN (CARVALHO, 2015, web) afirma que "essa busca vem da necessidade de uma conexão maior do indivíduo com o próximo e com o ambiente que o cerca, retirando excessos, priorizando a essência das coisas". Compreendendo as tendências norteadoras do desenvolvimento de produtos e serviços com foco nas cidades, bem como as que evidenciam o comportamento dos indivíduos, faz-se necessário conhecer o público alvo deste projeto, visto que ao assimilar seu estilo de vida, desejos e necessidades, é mais viável desenvolver soluções que efetivamente supram seus anseios.

\subsection{PÚBLICO ALVO}

Pessoas preocupadas com a sua qualidade de vida, que buscam por alternativas mais sustentáveis e eficientes. Assim podem ser sinteticamente os indivíduos alvo deste projeto. Conforme observado, o caos instaurado nas grandes cidades está elevando os níveis de stress e doenças mentais nos cidadãos em todo o mundo.

Inspirado na macrotendência Utopias Cotidianas, o público alvo deste projeto reside em ambientes verticalizados, são jovens adultos, com ou sem filhos, que valorizam as recordações e os prazeres simples da vida. Vivem em espaços pequenos e utilizam da criatividade para adaptar suas necessidades diárias. Possuem uma vida agitada, permanecendo a maior parte do tempo fora do ambiente residencial. Quando em seus lares, gostam de relaxar e aproveitar bem as horas de descanso. Aproveitam o dia com suas famílias, realizam atividades físicas, preocupam-se com a alimentação e com o bem-estar. Adeptos ao movimento slow food, que é contrária à padronização alimentar, valorizando o "prazer da alimentação, utilizando produtos artesanais de qualidade. Conhecendo as necessidades, desejos e características do cotidiano do público é possível projetar soluções adequadas à sua realidade. Nesse contexto, o próximo tópico evidencia o desenvolvimento projetual, apresentando as alternativas para aproveitar o potencial do lixo, o reuso de recursos naturais para efetivação de um ambiente compartilhado em espaços residenciais verticalizados.

\subsection{DESENVOLVIMENTO PROJETUAL}

Visando os conceitos de verticalização das cidades e o aumento da migração para cidade por parte dos indivíduos, percebe-se um cenário preocupante. A produção de lixo nos espaços urbanos vem aumentando e ao considerar a destinação incorreta, o cenário é ainda mais preocupante, vistos os inúmeros malefícios que estas questões trazem para a qualidade de vida dos cidadãos e em consequência ao ambiente. Outro fator preocupante é o consumo de água que aumenta diariamente. As alterações 
climáticas, o desperdício e o descaso para com o meio ocasionam uma crise no abastecimento. Considerando tais questões e as tendências no desenvolvimento de produtos, serviços e comportamento do consumidor, propõem-se alternativas para criação de possibilidades que resultem na melhora gradual deste cenário.

Diante desse contexto, propõe-se um ambiente compartilhado para espaços habitacionais verticalizados. Uma horta compartilhada, localizada no terraço dos prédios, onde moradores poderão desfrutar de um espaço verde agradável, em meio ao cinza da cidade. Aliado ao movimento Slow Food, os condôminos poderão usufruir de alimentos orgânicos, de produção própria, valorizando a cultura, tradições e as pessoas do local. Além disso, poderão aproveitar um espaço de convivência, em que poderão interagir com pessoas que compartilham dos mesmos princípios, criando vínculos e desenvolvendo uma vida em comunidade.

A localização da horta compartilhada no terraço dos edifícios foi inspirada em pesquisas que apontam benefícios na projeção de telhados verdes. Cita-se o projeto: telhados verdes solares, introduzido em uma escola pública de Nova lorque. Os professores utilizam o espaço para disseminar questões sobre energia limpa, além de integrá-los com a natureza. Neste contexto, Martin (2015, web) evidencia que "as pessoas tendem a ser mais saudáveis, mais felizes e ter uma vida mais duradoura em áreas com acesso a natureza, incluindo espaços urbanos com áreas verdes".

Para realização deste espaço compartilhado, propõe-se uma estrutura predial readequada para um estilo de vida sustentável. A primeira solução é a utilização do potencial do lixo orgânico como abastecimento de adubo para a horta. Visando tal utilização, os apartamentos serão equipados com trituradores de resíduos orgânicos. Durante a trituração, este lixo perderá volume de líquido que irá para o esgoto, já a massa será enviada para caixas coletoras localizadas no terraço do prédio, via dutos instalados junto às instalações prediais. Este lixo será reservado em uma composteira de resíduos secos, que é a mistura do lixo orgânico com material seco como palha, folhas secas e serragem de madeira pura, neste processo, o húmus fica pronto para utilização em dois ou três meses. Neste período, não há recolhimento de chorume, possibilitando a produção de adubo para a horta e, sendo assim, colaborando para com a redução de gases na atmosfera e de lixo em locais inadequados.

A segunda adequação apresentada está relacionada ao reuso da água das lavadoras de louça e roupa, água do banho e da pia da cozinha. Ressalta-se que a água da chuva também será coletada para auxiliar nas demandas. Em ambas as situações, a água passará por filtros, a fim de realizar o tratamento necessário para torná-la apta à irrigação da horta compartilhada, jardins, limpeza das áreas comuns e utilização nas descargas dos apartamentos. A água de reuso coletada, será destinada para uma cisterna, onde ficará estocada com tratamento constante. De acordo com Munhoz (2006) devem ser consideradas todas as finalidades da água de reuso, como lavação dos pisos, calçadas, irrigação, descarga de banheiro ou ainda tratamento de efluentes.

Sugere-se como complemento projetual, a implementação de outras alternativas para melhoria da qualidade de vida nos espaços residenciais verticalizados. Visando a geração de fontes de energia renovável, evidencia-se a possibilidade da transformação do esgoto em energia. Tal alternativa utiliza os dejetos sólidos que são eliminados como combustível energético. O gás metano $(\mathrm{CH} 4)$, dez vezes mais poluente que o gás carbônico (CO2), resulta da decomposição anaeróbica dos compostos em uma estação de tratamento, que realiza tal processo de forma 
inodora. De acordo com Tonon (2010) no distrito de Didcot, Reino Unido, mais de duzentas casas são abastecidas com esse tipo de energia renovável para alimentação dos sistemas de calefação, o que gera uma economia energética considerável e diminui a incidência destes gases na atmosfera. Outro exemplo, é a praça Park Spark, em Cambridge. Os moradores conviviam com o problema dos dejetos de cães que ficavam diariamente expostos no parque. Dessa forma após estudos o designer Mattew Mazzota desenvolveu um projeto sustentável que transforma todos os dejetos em fonte de energia para a praça, alimentando toda a rede de iluminação.

Baseando-se no cenário, nas tendências e no público deste projeto, percebeuse a possibilidade de criação de um ambiente compartilhado de horta orgânica. Visto que as tendências de comportamento do computador apontam para o resgatar das experiências nostálgicas de contato com a natureza, bem como as tendências de desenvolvimento de produtos e serviços apontam para a necessidade de trazer a natureza para dentro dos espaços urbanos e a criação de espaços compartilhados. A qualidade de vida atual dos indivíduos, reflete o caos das cidades, é preciso alterar a configuração deste sistema, para que ao se projetar os anos futuros, os indivíduos possam residir em um ambiente melhor e mais sustentável.

\section{CONCLUSÃO}

A análise das questões relacionadas a destinação e tratamento do lixo orgânico, bem como o descaso para com os recursos naturais, alertam para a maneira precária que estas questões estão sendo tratadas, tanto pela sociedade quanto pelas autoridades. Visualiza-se a necessidade dos indivíduos se conscientizarem da importância de investirem esforços para melhoria destes pontos, visando um futuro melhor. Acredita-se que se o descaso continuar, nos próximos anos o planeta poderá entrar em colapso, dificultando a vivência e a qualidade de vida.

Inspirado no comportamento e estilo de vida sustentável, derivados da macrotendência Utopias Cotidianas, foi proposta uma alternativa de construção vertical que potencializa a utilização do potencial do lixo e reuso de recursos naturais em ambientes residenciais verticalizados, visando a criação de uma área compartilhada, conforme tendência apontada. Tais questões resultaram no desenvolvimento de uma horta orgânica compartilhada, estimulando o consumo de alimentos saudáveis, propiciando uma melhor qualidade de vida e estimulando a vivência entre pessoas.

O potencial do lixo orgânico foi pensado como combustível para horta, visto que todo lixo gerado no condomínio será armazenado em caixas coletoras para alimentação de uma composteira que servirá de adubo para horta. O reuso de recursos naturais visa o reaproveitamento da água das lavadoras de louça e roupa, água do banho e torneira da cozinha, aliado à coleta da água da chuva para irrigação da horta, jardins, limpeza das áreas comuns do condomínio e utilização nas descargas dos apartamentos. Estimula-se dessa forma, uma atitude mais sustentável dos condôminos, que vivenciam na prática como o pensamento sustentável pode elevar a qualidade de vida e transformar ambientes. Objetiva-se ainda elencar os espaços verdes nos ambientes urbanos, ideia baseada na tendência Urban Jungles, propiciando o contato com a natureza e a prática de atividades nostálgicas, como o mexer com a terra. Tais atitudes proporcionam um formato mais sustentável de vida, mesmo em ambientes totalmente urbanos. 
Conclui-se que ao adotar medidas sustentáveis nos espaços verticalizados das cidades, as pessoas poderão desfrutar de ambientes mais estimulantes e inspiradores. As crianças poderão vivenciar o contato com natureza e conscientizar-se desde pequenas sobre a importância de cuidar da cidade. O caos urbano atual pode ser revertido se atitudes como estas começarem a ser executadas. Acredita-se que uma mudança gradual pode resultar em uma transformação global.

\section{REFERÊNCIAS}

ANDREU, Vicente. Água para as Cidades Brasileiras. Disponível em: <http://www2.ana.gov.br/Paginas/imprensa/artigos.aspx>. Acesso em: 12 nov. 2015.

BRASIL. Segundo Unesco, mundo precisará mudar consumo de água. Disponível em: http://www.brasil.gov.br/meio-ambiente/2015/03/segundo-unesco-mundo-precisaramudar-consumo-de-agua. Acessado em: 13 nov. 2015.

CARO, C. M.; RIVAS, J. L. Arquitetura urbana: elementos de teoria y diseño. 2. ed. Madrid: Bellisco, 1990.

CARVALHO, Elaine. Entre megatendências, a busca de prazeres cotidianos. Disponível em: <http://www.pagina22.com.br/2014/10/03/entre-megatendencias-a-busca-deprazeres-cotidianos/>. Acesso em: 15 nov. 2015

Consumo de água por habitante no Brasil é estável. Disponível em:

<http://www.abes-mg.org.br/visualizacao-de-clippings/pt-br/ler/2154/consumo-deagua-por-habitante-no-brasil-e-estavel>. Acesso em: 13 nov. 2015.

FERRO; Shaunacy. 6 Major Design Trends Shaping City Life In 2015. Disponível em: $<$ http://www.fastcodesign.com/3040823/6-major-design-trends-shaping-city-life-in2015>. Acesso em: 20 nov. 2015.

GARCIA, Natália. Cidades para pessoas: Natalia Garcia TEDxFloripa 2013. Disponível em: <http://www.youtube.com/watch?v=GNaovn4ta7M>. Acesso em: 11 abr. 2015.

IBGE. Censo 2010: população do Brasil é de 190.732.694 pessoas. Disponível em: $<$ http://saladeimprensa.ibge.gov.br/noticias?view=noticia\&id=1\&busca=1\&idnoticia=1 766>. Acesso em: 24 abr. 2015

LYNCH, Kevin. A imagem da cidade. São Paulo: Editora WMF Martins Fontes, 2011. MARTIN, Kirt. Paisagismo: a chave para o futuro de nossas cidades. Disponível em: <http://www.archdaily.com.br/br/772473/paisagistas-a-chave-para-o-futuro-dasnossas-cidades>. Acesso em: 20 nov. 2015.

Movimento Slow Food. Disponível em <http://www.slowfoodbrasil.com/slowfood/omovimento>. Acesso em: 18 nov. 2015.

MUNHOZ, Fabrício d'Stefano. Reuso de água em residências de pequeno e médio porte com sistema pré fabricado. São Paulo, 2006.

NUCCI, J. C. Qualidade ambiental e adensamento urbano. Curitiba: Edição do autor, 2008. Disponível em: <www.seer.ufu.br/index.php/caminhosdegeografia/article

/.../8886>. Acesso em: 21 nov. 2015.

Pantone view home+interiors 2015. Disponível em: <http://www.pantone.com/downl 
/pvh/PANTONEVIEW_home interiors_2015.pdf>. Acesso em: 15 nov. 2015.

População mundial. Disponível em: <http://www.worldometers.info/br/>. Acesso em: 15 nov. 2015.

Problema pode ser resolvido de diversas maneiras. Disponível em:

<http://www.ecycle.com.br/component/content/article/35/524-voce-sabe-o-quefazer-com-lixo-organico.html>. Acesso em: 12 nov. 2015.

PUBLICITTA. Gafisa por um novo estilo de morar. Disponível em:

$<$ http://www.revistapublicitta.com.br/atitude/tendencias/gafisa-por-um-novo-estilode-morar/>. Acesso em: 20 nov. 2015.

SANTOS, Luiz Eduardo Neves dos. Verticalização urbana e segregação socioespacial: Crise da cidade quadricentenária. In: CODE - Conferência do Desenvolvimento, I, 2011, Brasília - DF. Anais... Brasília: IPEA, 2011.

SANTOS, M. Técnica, espaço, tempo: globalização e meio técnico-científico informacional. 2. ed. São Paulo: Editora Hucitec, 1996.

. Metamorfose do espaço habitado. São Paulo: Editora Hucitec, 1997.

SÃO PAULO NEGÓCIOS. A cidade que mais cresce em competitividade. Disponível em: $<$ http://www.spnegocios.com/pt-br/por-que-sao-paulo/cidade-que-mais-crescecompetitividade>. Acesso em: 25 abr. 2015.

Segundo o portal WGSN, vida simples e conectada à natureza é tendência de comportamento. Disponível em: <http://revistadonna.clicrbs.com.br/moda/segundoo-portal-wgsn-vida-simples-e-conectada-a-natureza-e-tendencia-decomportamento/>. Acesso em: 15 nov. 2015.

SOUZA, M. A. A. A identidade da metrópole. São Paulo: Hucitec, 1994.

The urban jungle. Disponível em: <http://www.atkinsglobal.com/ /media/Files/A/ Atkins-Global/Attachments/sectors/environmental/library-docs/angles-articles/theurban-jungle.pdf>. Acesso em: 15 nov. 2015.

UNFPA. State of world population 2007: unleashing the potential of urban growth. New York: UNFPA, 2007.

VICTORINO, Celia Jurema Aito. Planeta água morrendo de sede: uma visão analítica na metodologia do uso e abuso dos recursos hídricos. Porto Alegre. Edipucrs 2007. 